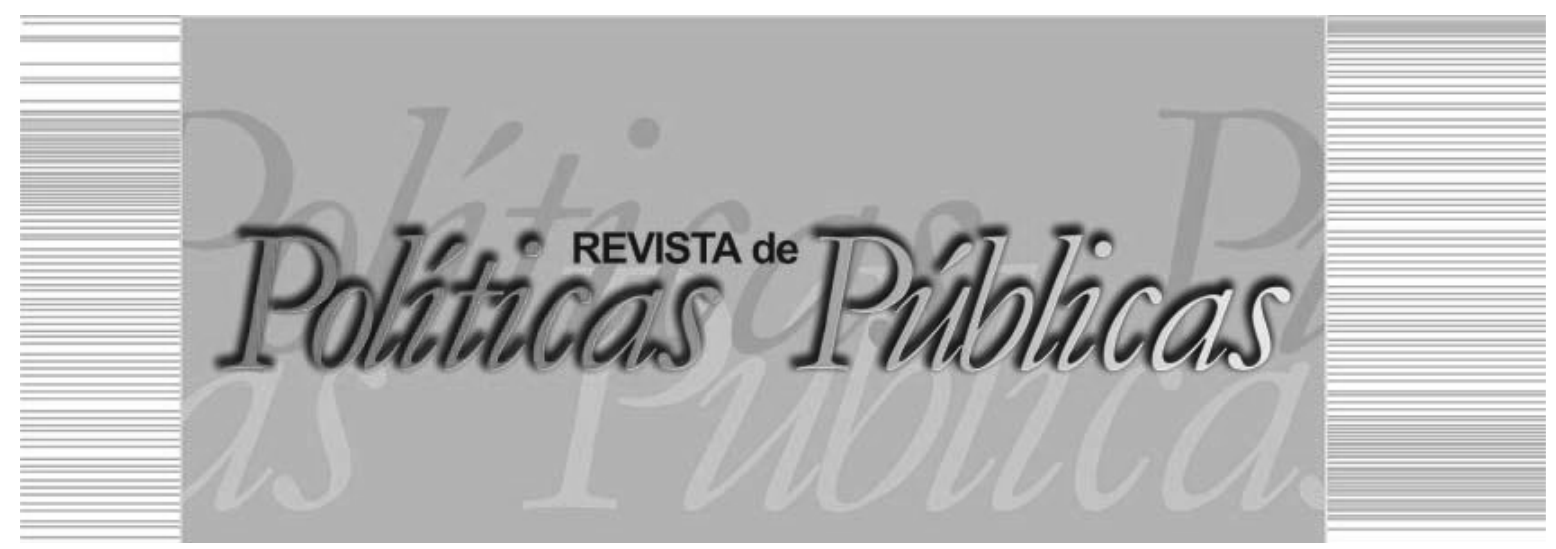

\title{
ENTRE COPACABANA E MARQUESS DE SAPUCAI: OS rumos dos incentivos culturais no Rio de Janeiro
}

\author{
Mauro Macedo Campos ${ }^{l}$ \\ Luiza Oliveira Marquezine ${ }^{2}$
}

\section{Resumo}

Este artigo analisa o funcionamento da lei de incentivo cultural do estado do Rio de Janeiro, a partir dos projetos aprovados. Trata-se de uma política pública com um caráter híbrido e sem coordenação federativa, que conjuga os setores, público e privado, através de leis de incentivo fiscal. Além da lei federal há outras tantas nas diversas subunidades de governo. São legislações editadas com regras e padrões próprios. Este artigo busca, portanto, um entendimento sobre a relação dos produtores culturais com a lei de incentivo fiscal no estado do Rio de Janeiro e analisa o uso da legislação em relação à aprovação dos projetos culturais entre os anos de 2013 e 2016. O banco de dados dos projetos é construído a partir dos diversos editais e publicações nos diários oficiais, e conclui que os resultados apontam uma concentração dos recursos em poucos projetos culturais e sediados na capital do estado.

Palavras-chave: Políticas culturais, leis de incentivo, subunidades de governo, concentração de recursos.

Doutorado em Ciência Política, Professor do Programa de Pós-Graduação em Sociologia Política, da Universidade Estadual do Norte Fluminense Darcy Ribeiro (UENF). E-mail: mauromcampos@yahoo.com.br / Endereço: Av. Alberto Lamego, 2000 - Campos dos Goytacazes - RJ. CEP 28013-600.

2 Bacharel em Administração Pública, Pesquisadora do Programa de Estudos Culturais, Linguagens e Arte, da Universidade Estadual do Norte Fluminense Darcy Ribeiro (UENF). E-mail: luizaomarquezine@hotmail.com / Endereço: Av. Alberto Lamego, 2000 - Campos dos Goytacazes - RJ. CEP 28013-600 


\title{
BETWEEN COPACABANA AND MARQUÊS DE SAPUCAÍ:
} the directions of cultural incentives in Rio de Janeiro

\begin{abstract}
This article analyzes the operation of the cultural incentive law of the state of Rio de Janeiro, based on the approved projects. It is a public policy with a hybrid character and without federative coordination, that conjugate the sectors, public and private, through laws of fiscal incentive. In addition to federal law there are as many others different subunits of government. They are editions of laws with their own rules and standards. This article seeks to understand the relationship between cultural producers and the incentive legislation in the state of Rio de Janeiro. The study analyzes the use of legislation in relation to the approval of cultural projects between the years of 2013 and 2016. The database of the projects was built from the various edicts and publications in the official journals. The results indicated a concentration of resources in few cultural projects and sediate in the capital of the state.

Key words: Cultural policies, Incentive laws, Subunits of government, Concentration of resources.
\end{abstract}

\section{INTRODUÇ̃̃O}

A cultura é um termo polissêmico. Envolve uma gama de significados que se relacionam com hábitos, costumes, sociabilidade entre os indivíduos. Nas palavras de Isaura Botelho (2001, p. 74), a "[...] cultura é tudo que o ser humano elabora e produz, simbólica e materialmente falando". Como uma fração desse universo, as políticas públicas culturais referem-se à expressão do trabalho de representação, levando em consideração os valores compartilhados socialmente. Definem-se pelas suas funções, instrumentos e meios para a realização de direitos culturais, reconhecimento de modos de saber, fazer e viver, podendo se relacionar com ideias de cidadania, de reconhecimento social, a produção simbólica e o fazer artístico. (RUBIM, 2008). A valorização da cultura que está contida no cotidiano da sociedade e estimula o desenvolvimento social. (SILVA; MIDLEJ, 2011). É nesse sentido que se percebe o caráter central das políticas públicas de cultura como sendo uma exigência das sociedades modernas. (CALABRE, 2007).

Acontece que a cultura enquanto política pública padece de coordenação federativa. Não há mecanismos efetivos que alinhem os propósitos e programas entre os entes federados de forma descentralizada e coordenada. Também não há uma transferência constitu- 
ENTRE COPACABANA E MARQUESS DE SAPUCAÍ: os rumos dos incentivos culturais

no Rio de Janeiro

cional de recursos para as subunidades de governo, o que a coloca em uma espécie de balcão de recursos, sejam públicos ou privados. Cada um, mercado e estado, busca para si alguma solução que lhes permita executar essa política cultural, seja ela de caráter público ou puramente mercadológico. No entanto, atrair a atenção e, sobretudo, os recursos do mercado, são necessários estímulos para que se possam financiar os projetos culturais. O setor público intervém neste segmento através da renúncia tributária oferecida ao setor privado para investir nessa área. (DURAND; GOUVEIA; BERGMAN, 1997).

Para este artigo a pesquisa se baseou na cultura como consumo. Um bem público, que se relaciona cada vez mais com mercado, além de ser mais um fator gerador de renda. (CALABRE, 2007; JESSOP, 2009). A cultura pode, então, ser vista como um negócio. É sob essa perspectiva que Isaura Botelho (2001) chama atenção, ao reforçar que a questão do financiamento de projetos culturais autônomos, por meio da renúncia tributária, assumiu o centro dos debates sobre essa política pública. Assim, de acordo com a autora, seja pela restrição orçamentária dos governos ou mesmo pela omissão deliberada, os rumos da política cultural ficaram a cargo do setor privado. Acontece que tais questões não podem ser observadas isoladamente ou apenas pelo prisma do orçamento do governo federal, que acaba sendo o principal alvo dos debates sobre a renúncia tributária no que se refere às leis de incentivo à cultura.

Os demais entes federados, sobretudo os estados, não podem ser deixados de lado em toda essa discussão. São 27 legislações estaduais distintas sobre o incentivo fiscal à cultura, que se espalharam pelo país. Todas têm por base um dos impostos mais relevantes do país, em termos de volume de recursos, que é o Imposto sobre Circulação de Mercadorias e Serviços (ICMS). E é sobre a descentralização desse formato liberal de condução dessa política pública que se pretende conduzir os argumentos deste artigo. Mais especificamente em relação ao aparato da lei estadual de incentivo à cultura do estado do Rio de Janeiro e os seus desdobramentos no que se refere aos efeitos práticos dessa legislação.

As leis de incentivo à cultura, nos moldes como estabelecido pelas legislações vigentes representam, de certa forma, uma transferência das atribuições do Estado, em custear essa política, para o setor privado. Trata-se de um instrumento pelo qual o estado (nos três 
níveis da federação) abre mão de parte da sua arrecadação tributária para o setor privado, que investe em projetos culturais. O Estado se incumbe de aprovar o projeto cultural para a captação de recursos e controlar a sua execução. (SANTOS; DE PAULO, 2014). Equivale, portanto, a um financiamento indireto da política pública. Esse caráter mais liberal das regras transfere ao produtor cultural o ônus da captação dos recursos para o custeio do seu projeto junto ao mercado. Assim, a partir dos anos de 1980, o Brasil assume uma postura liberal de política cultural, que se materializa na busca de patrocínio e investimento privado para o setor. Adota-se, então, o mesmo modelo dos países europeus e dos Estados Unidos, o de renúncia fiscal. (MOISÉS, 1998).

Em termos mais gerais, as leis de incentivo à cultura, seja no âmbito federal, estaduais ou municipais, estimulam a parceria do poder público com a iniciativa privada no sentido de fomentar as ações culturais em cada região e nos diversos segmentos culturais. Portanto, refere-se a um jogo de soma positiva, onde os atores envolvidos nesse processo de produção cultural tendem a se beneficiar reciprocamente. A proposta deste artigo caminha no sentido de buscar um entendimento sobre a relação dos produtores culturais com a lei de incentivo cultural no âmbito estadual. O estudo visa identificar o uso, pelo mercado cultural, da lei de incentivos fiscais para realização de projetos culturais no estado do Rio de Janeiro, entre os anos de 2013 e 2016.

\section{AS LEIS DE INCENTIVO E A CULTURA COMO UM NEGÓCIO}

A dinâmica das leis de incentivo à cultura no Brasil ocorre em três etapas principais: na primeira, os governos federal, estaduais ou municipais aprovam os projetos submetidos; na segunda, os proponentes (produtores culturais) captam os recursos no mercado e se responsabilizam junto ao governo pelos projetos; e, por último, os investidores/patrocinadores (empresa ou pessoa física) que aplicam seus recursos nesses projetos culturais aprovados passam a ter direito aos benefícios fiscais previstos nas respectivas leis de incentivo cultural.

O governo federal atua por meio do Ministério da Cultura (MinC) ou da Agência Nacional de Cinema (Ancine). A legislação federal vigente no país, a Lei $\mathrm{n}^{\mathrm{o}}$ 8.313, 23 de dezembro de 1991, 
ENTRE COPACABANA E MARQUESS DE SAPUCAÍ: os rumos dos incentivos culturais

no Rio de Janeiro

mais conhecida como Lei Rouanet ${ }^{1}$, tem como objetivo promover, apoiar, incentivar a produção cultural e artística brasileira através do benefício fiscal. Estimula a iniciativa privada a investir no setor cultural, com recursos oriundos da renúncia fiscal do Imposto de Renda (IR), seja para pessoas jurídicas ou físicas. As leis federais de incentivo à cultura acabaram influenciando os demais entes federados a adotarem critérios parecidos, com seus respectivos impostos. (DURAND; GOUVEIA; BERGMAN, 1997). As variações ocorrem de acordo com o tipo do imposto e porcentagem de renúncia, sendo que os governos estaduais e municipais atuam por intermédio de suas Secretarias de Cultura ou Secretarias de Educação. A renúncia fiscal nos estados ocorre com o Imposto sobre Circulação de Mercadorias e Serviços (ICMS), e, nos municípios, com o Imposto sobre Serviços de Qualquer Natureza (ISSQN) ou Imposto Predial e Territorial Urbano (IPTU). (MOISÉS, 1998; COSTA; MEDEIROS; BUCCO, 2017). Vale lembrar que não são legislações excludentes. A submissão de um projeto cultural a uma determinada lei de incentivo cultural não elimina a possibilidade de reapresentá-lo a outra lei, em outra esfera de governo. As variações principais ocorrem no tributo a ser deduzido os investimentos, no caso dos estados e municípios. Tal como está exemplificado no Quadro 1.

Quadro 1 - Leis de incentivo e as esferas do Governo

\begin{tabular}{|c|c|c|c|c|}
\hline Governos & $\begin{array}{l}\text { Instâncias } \\
\text { governamentais } \\
\text { responsáveis por } \\
\text { aprovar os projetos }\end{array}$ & $\begin{array}{l}\text { Leis de } \\
\text { Incentivo } \\
\text { Fiscal }\end{array}$ & Impostos devidos & $\begin{array}{c}\text { Patrocinadores e/ } \\
\text { ou Investidores }\end{array}$ \\
\hline Federal & $\begin{array}{l}\text { Ministério da Cultura } \\
\text { (MinC) } \\
\text { Agência Nacional de } \\
\text { Cinema (ANCINE) }\end{array}$ & $\begin{array}{l}\text { Lei Rouanet } \\
\text { Lei do } \\
\text { Audiovisual }\end{array}$ & $\begin{array}{l}\text { Imposto de Renda } \\
\qquad(\mathrm{IR})\end{array}$ & $\begin{array}{c}\text { Empresas } \\
\text { públicas el } \\
\text { ou privadas e } \\
\text { pessoa física }\end{array}$ \\
\hline Estaduais & Secretarias de Cultura & Lei do ICMS & $\begin{array}{l}\text { Imposto sobre } \\
\text { Circulação de } \\
\text { Mercadorias e } \\
\text { Serviços (ICMS) }\end{array}$ & $\begin{array}{l}\text { Empresas } \\
\text { públicas el } \\
\text { ou privadas e } \\
\text { pessoa física }\end{array}$ \\
\hline Municipais & $\begin{array}{c}\text { Secretarias de Cultura } \\
\text { e/ou Fundações de } \\
\text { Cultura }\end{array}$ & Lei Municipal & $\begin{array}{c}\text { Imposto sobre } \\
\text { Serviços de } \\
\text { Qualquer Natureza } \\
\text { (ISSQN) } \\
\text { Imposto Predial e } \\
\text { Territorial Urbano } \\
\text { (IPTU) }\end{array}$ & $\begin{array}{l}\text { Empresas } \\
\text { públicas el } \\
\text { ou privadas e } \\
\text { pessoa física }\end{array}$ \\
\hline
\end{tabular}

Fonte: Informações da Secretaria de Estado de Cultura do Rio de Janeiro. 
As leis de incentivo à cultura, de acordo com Isaura Botelho (2001), resultaram de uma mobilização de artistas e produtores que se viram obrigados a sair em busca de patrocínio privado para o desenvolvimento de suas atividades. Foram criadas associações, tanto para a promoção direta de projetos de natureza artística e cultural, quanto para auxiliar a manutenção de instituições como museus, teatros, cinematecas, entre outras. A partir da criação de organismos descentralizados pode-se observar um movimento em direção a uma diversificação de atividades fora da tutela do poder público.

A criação das leis de incentivo à cultura parte de uma concepção na qual o setor privado (indivíduos e empresas), com o decorrer do tempo, em tese, criaria uma consciência da importância (ou mesmo o hábito) de patrocinar ou investir no setor cultural. No primeiro momento, todos se beneficiariam: o estado repassaria para o setor privado uma parcela das suas atribuições. As empresas investiriam no setor uma parte do imposto que pagariam ao poder público e teriam em contrapartida, o marketing de suas empresas (públicas ou privadas) veiculado ao produto cultural (DURAND; GOUVEIA; BERGMAN, 1997; SANTOS; DE PAULO, 2014). Entretanto, as tais expectativas não se evidenciaram. Na prática prevaleceu uma lógica mais mercadológica, em que se sobressairiam os ganhos com o marketing cultural, decorrente da renúncia fiscal. (MOISÉS, 1998). Ou seja, se o benefício fiscal pode ser considerado como sendo uma variável independente, o seu contraponto, a variável dependente, que são os projetos culturais a serem financiados, esses tendem a buscar mercados consumidores maiores e de maior poder aquisitivo. Uma espécie de efeito não esperado da política, a partir dessa lógica liberal. Mas que se trata de uma causalidade relativamente simples: o grande investidor da cultura, as empresas, se vale da renúncia fiscal, mas tem os olhos voltados para os consumidores daqueles produtos culturais financiados que, em boa medida, são os próprios consumidores das suas marcas. Com efeito, tem-se que o maior volume de recursos para os patrocínios/investimentos aos projetos culturais - frutos da parceria entre Estado e empresas privadas (ou públicas) -, não teve como destino final os produtores culturais situados nos municípios interioranos ${ }^{2}$.

Parece, portanto, uma lógica que se retroalimenta: os proponentes com maiores informações e acesso estão nos grandes centros, que aglomeram os maiores investidores em projetos culturais, que são as grandes corporações ${ }^{3}$, e que por sua vez, concentram o públi- 
ENTRE COPACABANA E MARQUESS DE SAPUCAÍ: os rumos dos incentivos culturais no Rio de Janeiro

co consumidor desses projetos culturais e das marcas dessas empresas. E se tal lógica é percebida na lei federal de incentivo à cultura, parece ser mais concentrada ainda nas leis estaduais, em que pese 0 menor volume de recursos a ser oferecido como renúncia fiscal.

Todavia, independentemente do âmbito de atuação, as leis de incentivo à cultura estimulam a parceria entre o público e o privado. No entanto, a subordinação das políticas de financiamento às ações culturais desenvolvidas reforça a supremacia do custeio empresarial em detrimento do estado. (RUBIM, 2013; COSTA; MEDEIROS; BUCCO, 2017).

Nesse sentido, na maioria das vezes, a própria estrutura das legislações que normatiza os incentivos fiscais, distancia um grande número de pequenos produtores culturais que não conseguem formatar projetos que atendam às exigências legais e, portanto, não usufruem desse benefício. (SANTOS; DE PAULO, 2014). Geralmente em municípios menores não há cursos profissionalizantes, seja em função de uma demanda pequena, ou por falta de apoio dos governantes, o que torna o problema para esses produtores, ainda mais agudo. Assim, a maior parcela dos beneficiários das leis de incentivo à cultura está concentrada nos grandes centros urbanos, o que reforça o caráter excludente que a legislação pode propiciar.

Desse modo, acaba por criar relações assimétricas que se caracterizam pelo acesso ao conhecimento e benefícios da legislação cultural, bem como a centralização das decisões nas mãos das empresas e a concentração no eixo Rio de Janeiro e São Paulo - no caso as duas capitais. (RUBIM, 2009). A região Sudeste concentra cerca de $80 \%$ dos recursos destinados pela lei de incentivo à cultura, contudo, nem de perto corresponde a $80 \%$ da população. Um contraponto é a região Norte, cujo apoio à cultura representa apenas $1 \%$ da captação nacional ${ }^{4}$ (SILVA; MIDLEJ, 2011). Nessa mesma linha, José Carlos Durand (2001, p. 25) argumenta que "[...] é muito frequente as Secretarias Estaduais concentrarem recursos nas capitais dos estados sobrepondo-se às respectivas Secretarias Municipais, enquanto faltavam visão e vontade sobre o que fazer no interior". É por essa perspectiva que se consolida o argumento deste artigo. 


\section{POLÍTICA CULTURAL NO ESTADO DO RIO DE}

JANEIRO: a descentralização do incentivo à cultura

A Secretaria de Estado de Cultura do Rio de Janeiro (SEC) organiza a política cultural do estado a partir de projetos e programas culturais. Segundo informações da SEC, existe a figura normativa do Fundo Estadual de Cultura, mas que ainda não foi regulamentado. O desenho das políticas de cultura adotado pela SEC pode ser observado no Quadro 2.

Quadro 2 - Projetos e Programas Culturais da Secretaria de Estado de Cultura do Rio de Janeiro

\begin{tabular}{|c|c|}
\hline $\begin{array}{l}\text { Projetos e Programas Culturais } \\
\text { (SEC/RJ) }\end{array}$ & Descrição \\
\hline Editais & $\begin{array}{l}\text { Incentivar, apoiar e fomentar atividades culturais em todo } \\
\text { o território do Rio de Janeiro. São várias as seleções } \\
\text { públicas, por meio de editais, em áreas como audiovisual, } \\
\text { artes visuais, cultura popular e museus. }\end{array}$ \\
\hline $\begin{array}{l}\text { Pontos de Cultura do Estado } \\
\text { do Rio de Janeiro }\end{array}$ & $\begin{array}{l}\text { Os Pontos de Cultura são definidos como iniciativas } \\
\text { culturais desenvolvidas pela sociedade civil que estão } \\
\text { sendo potencializadas pelo Governo Federal, através } \\
\text { do Programa Mais Cultura, em conjunto com o Governo } \\
\text { Estadual. }\end{array}$ \\
\hline Incubadoras Rio Criativo & $\begin{array}{l}\text { O projeto Rio Criativo - Incubadoras de Empreendimentos } \\
\text { da Economia Criativa do Estado do Rio de Janeiro foi } \\
\text { criado com o objetivo de estimular a consolidação de } \\
\text { empreendimentos criativos no estado. }\end{array}$ \\
\hline Novas Cenas & $\begin{array}{l}\text { A iniciativa promove a circulação de grupos teatrais e } \\
\text { musicais compostos por atores em formação, ou recém- } \\
\text { formados, por espaços do interior do Estado. }\end{array}$ \\
\hline Banda Larga & $\begin{array}{l}\text { Programa de Atualização para Bandas de Música do } \\
\text { Estado do Rio de Janeiro. }\end{array}$ \\
\hline Bibliotecas Parque & $\begin{array}{l}\text { Bibliotecas públicas multifuncionais em comunidades com } \\
\text { acesso imediato e fácil à informação. }\end{array}$ \\
\hline Sistema Estadual de Cultura & $\begin{array}{l}\text { Sistema estadual integrado ao nacional e aos sistemas } \\
\text { municipais. Em } 2015 \text { foi construída uma nova legislação } \\
\text { para a cultura fluminense. }\end{array}$ \\
\hline
\end{tabular}

Fonte: Informações da Secretaria de Estado de Cultura do Rio de Janeiro.

No conjunto de iniciativas da Secretaria de Estado de Cultura do Rio de Janeiro, em 2010 o governo lançou o Programa de Apoio ao Desenvolvimento Cultural (PADEC), dos municípios do 
ENTRE COPACABANA E MARQUESS DE SAPUCAÍ: os rumos dos incentivos culturais

no Rio de Janeiro

estado do Rio de Janeiro com o propósito de atuar nas seguintes áreas: qualificação da gestão pública da cultura, preservação do patrimônio material, fortalecimento da identidade cultural e melhorias na infraestrutura para a cultura local. Trata-se de um programa criado inicialmente para "[...] apoiar os 91 municípios, excluída a capital" (RIO DE JANEIRO, 2010), de modo estimular o setor cultural a nessas localidades, uma vez que há uma nítida concentração do mercado cultural na capital. (DURAND, 2001, p. 67). A estrutura funcional desse programa ocorre pelo empenho orçamentário da própria SEC e também pelo aporte financeiro do MinC. A adoção desse programa com um viés mais direcionado para as iniciativas e empreendimentos culturais no interior do estado indica a preocupação com uma situação prática, que é a concentração dos projetos culturais nos grandes centros. São nessas localidades que faltam recursos, de toda ordem, que se reflete o baixo número de projetos culturais aprovados pelas leis de incentivo. E esse é o mesmo cenário que se pode traçar nas mais de duas décadas de vigência da lei de incentivo cultural, tanto no âmbito federal como estaduais, como é o caso do Rio de Janeiro, objeto deste estudo.

Esse problema se associa à relação muito estreita entre público e privado na cultura, que reforça a dependência dos recursos privados e um significado mercadológico direcionado ao público consumidor de marcas que se valem desse marketing cultural. (COSTA; MEDEIROS; BUCCO, 2017).

No Estado do Rio de Janeiro a lei de incentivo à cultura segue os mesmos preceitos da legislação federal, como um mecanismo de fomento à cultura e que institui o incentivo fiscal para empresas contribuintes, variando o tributo, que passa a ser o ICMS. Os demais procedimentos mantiveram-se praticamente os mesmos, desde a aprovação dos projetos culturais aprovados pela Secretaria Estadual de Cultura, a captação de recursos junto ao setor privado e a prestação de contas.-

Vale dizer que, o arcabouço legal que define e orienta os incentivos fiscais ao setor privado em relação aos investimentos em projetos culturais no estado do Rio de Janeiro conta com uma série de leis, decretos e resoluções. A lei que deu origem a esses mecanismos de intervenção privada no custeio da cultura do Rio de Janeiro surgiu exatamente no mesmo ano da promulgação da Lei Rouanet, em 1992. Desde então, essa lei foi modificada a cada dez anos, sen- 
do a última lei editada em 2011. Já o Sistema Estadual de Cultura do Estado foi efetivado apenas em 2015, por lei específica. Afora esse emaranhado de leis, os mecanismos que determinam o funcionamento desse instrumento de política cultural são ordenados por cinco decretos que regulam desde a concessão de incentivos fiscais aos projetos culturais até o funcionamento do Fundo Estadual de Cultura. Vigoram também, uma resolução que disciplina a aplicação dos recursos públicos concedidos pela SEC e duas instruções normativas. São, portanto, doze normativas vigentes e vinte resoluções. Em meio a esse mix normativo que regula a política pública para a cultura no estado, há iniciativas que não são relacionadas ao mecanismo da lei de incentivo.

Assim, como a estrutura formal da legislação do Rio de Janeiro segue a lei federal, também os seus resultados. Ou seja, o investimento via lei estadual de incentivo àcultura mantém o mesmo padrão das leis federais cujos recursos da lei se concentram na capital do Rio de Janeiro. Isso ocorre por um arranjo combinatório entre o estado e o setor privado. O primeiro pela sua incapacidade de custear uma política pública de forma direta, e o segundo por levar sua imagem ao maior número de pessoas possível.

A legislação do Rio de Janeiro reforça essa premissa, ao se valer do dispositivo da Declaração de Intenção de Patrocínio (DIP), que se refere a um documento no qual o patrocinador "[...] formaliza seu compromisso de apoiar o projeto cultural e solicita concessão de benefício fiscal", além da "[...] comprovação de captação mínima equivalente a $40 \%$ do valor solicitado à Lei de Incentivo." (RIO DE JANEIRO, 2013, p. 7). Em termos mais técnicos, o incentivo fiscal de que trata a legislação do Rio de Janeiro, corresponde a 4\% do ICMS, a recolher em cada período para doações ou patrocínio de produções culturais de autores e intérpretes nacionais e $1 \%$ para patrocínio de produções culturais estrangeiras 5 . A Tabela 1 traz os valores concedidos na forma de benefício ao setor privado, pelo estado do Rio de Janeiro, em termos de renúncia fiscal.

Tabela 1 - Renúncia fiscal - Lei de incentivo à cultura do Rio de Janeiro (2009-2016)*

\begin{tabular}{c|c|c|c}
\hline \multirow{2}{*}{ Ano } & \multicolumn{1}{c}{$\begin{array}{c}\text { Benefício Fiscal } \\
\text { (em R\$) }\end{array}$} & \multicolumn{1}{c}{$\begin{array}{c}\text { Contrapartida } \\
\text { (em R\$) }\end{array}$} & $\begin{array}{c}\text { Concessão total } \\
\text { (em R\$) }\end{array}$ \\
\hline 2009 & $70.759 .052,27$ & $18.029 .954,07$ & $88.789 .006,34$ \\
\hline 2010 & $74.424 .326,26$ & $22.000 .173,55$ & $96.424 .499,81$ \\
\hline
\end{tabular}


ENTRE COPACABANA E MARQUESS DE SAPUCAÍ: os rumos dos incentivos culturais no Rio de Janeiro

\begin{tabular}{l|l|l|l}
\hline 2011 & $84.517 .869,14$ & $23.475 .218,54$ & $107.993 .087,68$ \\
\hline 2012 & $99.209 .939,00$ & $28.192 .454,00$ & $127.402 .393,00$ \\
\hline 2013 & $106.973 .350,57$ & $33.881 .881,58$ & $140.855 .232,15$ \\
\hline 2014 & $78.685 .942,88$ & $23.645 .979,10$ & $102.331 .921,98$ \\
\hline 2015 & $78.934 .358,00$ & $24.559 .848,08$ & $103.494 .206,08$ \\
\hline 2016 & $79.956 .877,50$ & $18.033 .821,13$ & $97.990 .698,63$ \\
\hline
\end{tabular}

Fonte: Informações da Secretaria do Estado de Cultura - Superintendência da Lei de Incentivo. Nota: $(*)$ Os valores não foram deflacionados.

Os valores apresentados pela SEC mostram dois anos destoantes dos demais, 2012 e 2013, em que os valores referentes à renúncia fiscal do ICMS do Rio de Janeiro tiveram uma elevação média próxima de $35 \%$, comparado aos anos anteriores da série. Na sequência da série, observa-se uma redução de (-23\%) em relação aos três últimos anos. Esse movimento acompanha claramente a perda orçamentária do estado Rio de Janeiro, no que se refere ao principal tributo estadual, em face da crise que assola o estado nos últimos anos. Vale ressaltar que os recursos apresentados pelo estado do Rio de Janeiro em forma de benefício fiscal, tratam de valores orçados, que serão executados a partir da real condição de aprovação dos projetos culturais, em quantidade e valores.

\section{A NORMA E A PRÁTICA DO INCENTIVO CULTURAL NO RIO DE JANEIRO}

Em termos operacionais, os projetos são inscritos no Sistema de Inscrição de Avaliação de Projetos (SIAP), a partir da publicação dos editais pela SEC . A Comissão de Aprovação de Projetos (CAP) fica encarregada pela avaliação dos projetos habilitados na etapa de parecer técnico. É composta por seis representantes da SEC e sete membros indicados pelo Secretário de Estado de Cultura. A escolha dos projetos a serem aprovados para usufruír dos benefícios da lei de incentivo à cultura do estado é dada a partir de critérios técnicos e de interesse público. (RIO DE JANEIRO, 2015). Há um conjunto de documentos obrigatórios: orçamento, cronograma de atividades, plano básico de distribuição, plano básico de divulgação, planejamento metodológico de formação cultural e declaração de intenção de patrocínio, a partir de um banco de empresas habilitadas a patrocinarem projetos via lei estadual de incentivo. Essa declaração tem 
uma função primordial para submissão do projeto, que pode refletir na sua aprovação.

O que se percebe, portanto, é um fosso burocrático que separa o produtor cultural, sobretudo aqueles dos municípios do interior, das formalidades das leis de incentivo à cultura, já na elaboração dos projetos culturais nos moldes estabelecidos pelos editais. É que, via de regra, estes produtores não se envolvem com tais questões de caráter mais burocrático, o que já estabelece uma barreira para o uso do mecanismo das leis culturais. Em muitos casos, essas barreiras são transpostas por escritórios especializados nessa temática. Esses entraves são mais agudos quando se trata de produtores culturais dos municípios do interior, onde este tipo de prestação de serviços especializados é escasso. A lógica liberal e fria presente nas leis de incentivo, na qual os produtores culturais teriam a mesma qualidade de acesso a este mecanismo de incentivo e financiamento aos seus projetos, na prática não se evidencia. É um mercado cultural que se aloca, principalmente, nas capitais e grandes centros, onde estão os escritórios que cuidam destes entraves burocráticos, e acabam sendo incomuns no interior.

Para a concessão do benefício fiscal é necessário que o projeto seja aprovado e que o patrocinador esteja cadastrado de acordo com as exigências estabelecidas pela SEC. Ou seja, para que ocorra aprovação do projeto cultural, há a exigência prévia de aceite, por parte da empresa que irá patrocinar aquele projeto. Portanto, no caso do Rio de Janeiro, há uma inversão na ordem, em que a captação ocorre antes mesmo da submissão do projeto. Esse mecanismo, por um lado, pode atuar como um facilitador ao produtor cultural, pois os eventuais patrocinadores já estão catalogados pela Secretaria. No entanto, isso pode também ser um fator inibidor aos produtores do interior, dada a falta de acesso a essas empresas.

Após essa rápida explanação sobre o roteiro formal para a elaboração e submissão de um projeto cultural pela lei de incentivo à cultura do Estado do Rio de Janeiro, na seção seguinte apresentaremos os resultados da aprovação dos projetos culturais. O intuito, aqui, é analisar esse extrato de aprovações, de modo que se possa identificar algumas questões, como áreas culturais privilegiadas, municípios e proponentes. Isso se torna importante na avaliação da lei de incentivo cultural enquanto um instrumento de política pública, de acesso universal aos produtores culturais, bem como o seu 
ENTRE COPACABANA E MARQUESS DE SAPUCAÍ: os rumos dos incentivos culturais

no Rio de Janeiro

caráter liberal, no qual se desloca a atribuição da política aos atores privados do mercado cultural, seja o proponente ou o patrocinador.

\subsection{Os projetos aprovados pelo incentivo cultural no Rio de Janeiro}

Esta seção busca mapear os resultados dos projetos aprovados pela lei de incentivo à cultura do Estado do Rio de Janeiro, para os anos de 2013 a 2016 e, a partir desse banco de dados, trazer informações que permitam analisar o perfil do incentivo concedido pela lei.

De antemão, merece que se destaque o percurso efetuado para se chegar a essas informações. Em consulta à Secretaria de Estado de Cultura, nos foi dito que os projetos de incentivo à cultura, aprovados para a captação, saem publicados no Diário Oficial do Estado do Rio de Janeiro (DOERJ), que por sua vez, estão disponibilizados no site da Secretaria de Estado de Cultura, por meio das decisões da CAP. As decisões são encaminhadas para as publicações no DOERJ, na data da publicação de cada aprovação, não de forma conjunta. Não há uma relação dos projetos aprovados. Há que se consultar os diários nas datas informadas pela CAP. Em cada publicação têm-se as informações de cada projeto. Portanto, o banco de projetos aprovados para os anos sob análise foi construído a partir da consulta dos vários diários oficiais indicados pela CAP.

Em termos operacionais, o governo do estado oferece como benefício tributário até o limite estabelecido de abatimento do ICMS recolhido pelo estado, que é orçado a cada ano. Também, anualmente, são lançados os editais aos produtores culturais, via lei de incentivo à cultura. A partir daí, tem-se que os produtores culturais (pessoa física ou jurídica) elaboram seus projetos com os respectivos orçamentos. A aprovação pode ser na sua totalidade do valor orçado pelo proponente ou uma fração do montante apresentado. Além de uma contrapartida exigida, que gira em torno de $22 \%$ da concessão total. Tais questões ajudam a explicar as eventuais diferenças entre as fontes consultadas, o DOERJ e a SEC.

A Tabela 2 evidencia a relação quantitativa dos projetos aprovados pela Secretaria de Cultura do Rio de Janeiro, para os anos analisados. Os dados apresentados referem-se aos projetos que foram aprovados, com os respectivos valores que podem ser captados, e que foram divulgados pelo DOERJ. Não significa, no entanto, que esses valores correspondem exatamente ao total orçado pelo projeto 
apresentado à SEC. Para essa tabela, os dados foram agrupados por projetos apresentados na capital e municípios do interior do estado.

Tabela 2 - Projetos aprovados lei de incentivo à cultura do Rio de Janeiro - capital e interior (2013-2016)*

\begin{tabular}{|c|c|c|c|c|c|c|}
\hline \multirow{2}{*}{ Ano } & \multicolumn{2}{|c}{ Rio de Janeiro - Capital } & \multicolumn{2}{c|}{ Interior do Rio de Janeiro } & \multicolumn{2}{c|}{ Total } \\
\cline { 2 - 7 } & $\begin{array}{c}\mathrm{N}^{0} \\
\text { Projetos }\end{array}$ & Valor (em R\$) & $\begin{array}{c}\mathrm{N}^{0} \\
\text { Projetos }\end{array}$ & Valor (em R\$) & Projetos & $\begin{array}{c}\text { Renúncia (em } \\
\mathrm{R} \$)\end{array}$ \\
\hline 2013 & 137 & $73.985 .706,63$ & 37 & $10.304 .888,90$ & 174 & $84.290 .595,53$ \\
\hline 2014 & 133 & $77.296 .542,98$ & 40 & $13.030 .078,49$ & 173 & $90.326 .621,47$ \\
\hline 2015 & 93 & $67.445 .788,00$ & 27 & $10.527 .409,62$ & 120 & $77.973 .197,62$ \\
\hline 2016 & 160 & $51.756 .688,02$ & 29 & $8.606 .533,50$ & 189 & $60.363 .221,52$ \\
\hline
\end{tabular}

Fonte: Elaborado pelos autores, conforme informações do Diário Oficial do Estado do Rio de Janeiro (várias edições).

Nota: $\left(^{*}\right)$ Os valores não foram deflacionados.

Os dados mostram uma concentração de projetos na capital nos quatro anos, em média de $80 \%$ no que se refere ao número de projetos aprovados, e uma média um pouco maior, de $86 \%$, em termos de valores destinados à renúncia fiscal do ICMS. O gráfico 1 deixa visualmente mais evidente esse distanciamento entre o número de projetos e os valores a eles aportados, entre a cidade do Rio de Janeiro e os municípios do interior do estado.

Gráfico 1 - Projetos culturais aprovados: capital e interior (2013-2016)

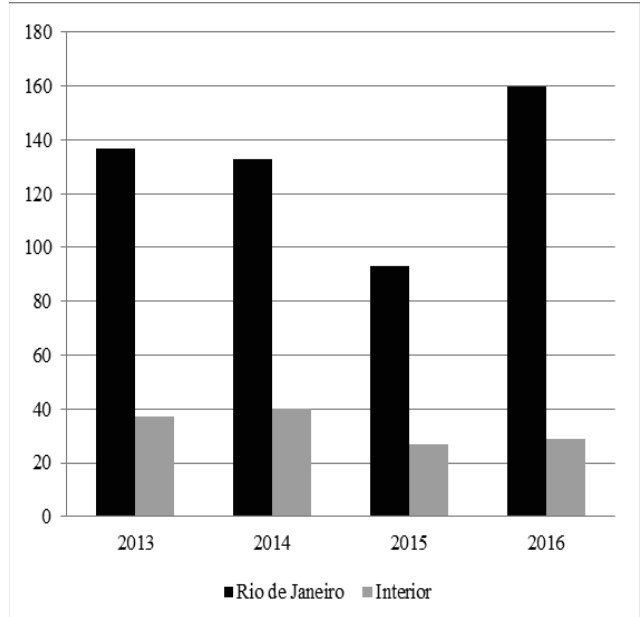


ENTRE COPACABANA E MARQUÊS DE SAPUCAÍ: os rumos dos incentivos culturais no Rio de Janeiro

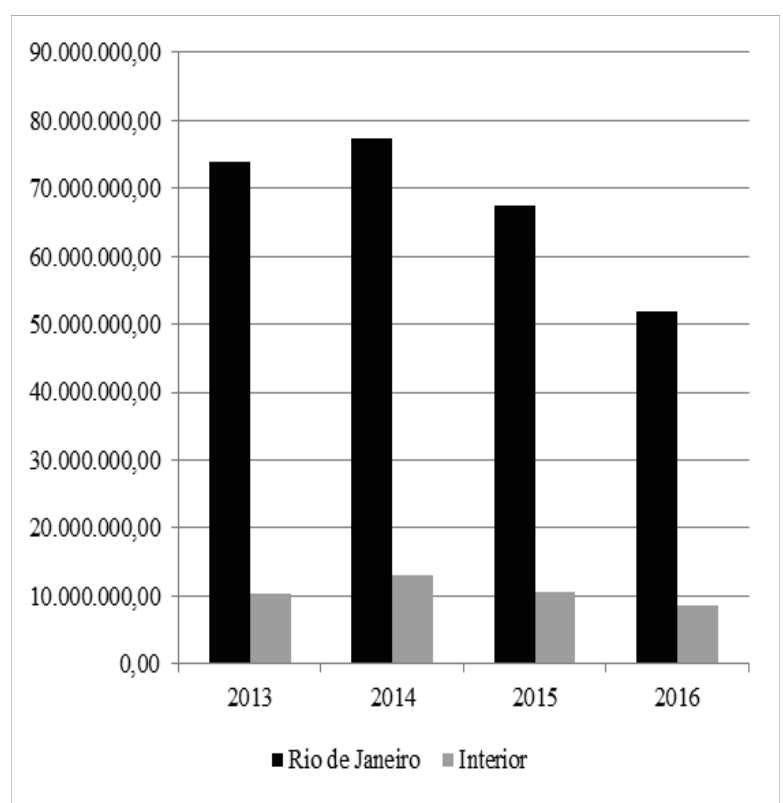

Fonte: Elaborado pelos autores, conforme informações do Diário Oficial do Estado do Rio de Janeiro (várias edições).

O Gráfico 2 traz os principais proponentes que tiveram seus projetos culturais aprovados pela CAP, nos editais da SEC de 2013 a 2016. Esse dado é importante porque além de ressaltar a concentração dos recursos da lei em alguns projetos, também mostra que esses proponentes encontram-se na cidade do Rio de Janeiro. Para a construção do gráfico 2 foram selecionados os cinco projetos culturais cujo valor aprovado fosse acima de $\mathrm{R} \$ 1,5$ milhão, em cada ano. Trata-se de um critério meramente analítico, sem nenhum rigor estatístico. Mais com a intenção de não tumultuar visualmente o gráfico com informações excessivas. 


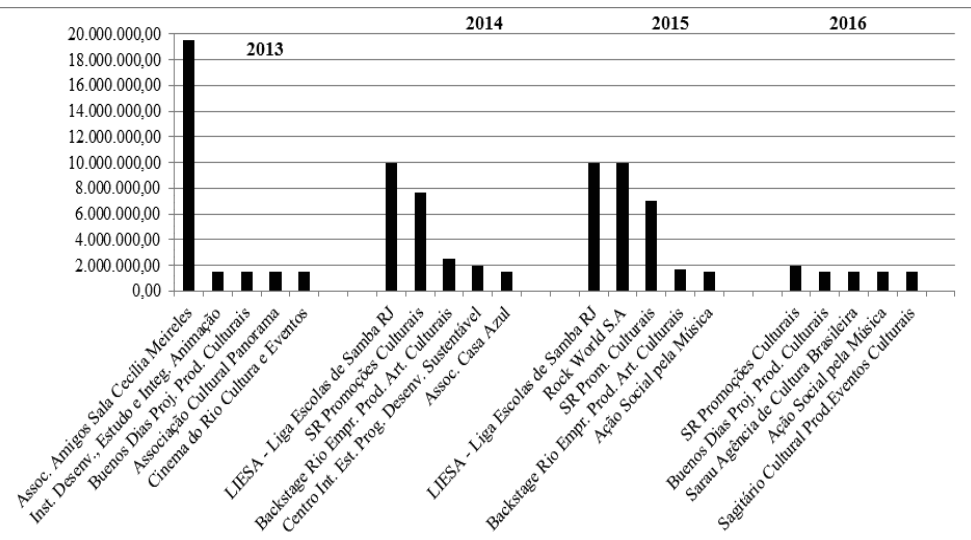

Fonte: Elaborado pelos autores, conforme informações do Diário Oficial do Estado do Rio de Janeiro (várias edições).

A análise individualizada dos projetos aprovados nos editais de cada ano traz informações relevantes sobre o funcionamento da lei de incentivo à cultura do Rio de Janeiro. Em 2013, a Comissão de Aprovação de Projetos destinou a um único proponente, o equivalente a $23,2 \%$ dos recursos da lei de incentivo à cultura. De um total de R \$ 84,3 milhões de recursos aprovados pela CAP, a Associação dos Amigos da Sala Cecília Meireles, aprovou R\$19,6 milhões para o projeto cultural, Reforma da Sala Cecília Meireles - Segunda Fase, na área de Equipamentos Culturais. Esse foi o maior valor aprovado ao longo de toda a série pesquisada para este artigo. Os valores destinados a esses cinco maiores projetos culturais equivalem a $30,3 \%$ de todo o orçamento para 2013.

No ano seguinte, em 2014, dois projetos culturais se sobressaíram. A Liga Independente das Escolas de Samba do Rio de Janeiro (LIESA), com o projeto cultural Samba Patrimônio Cultural do Brasil, com valor aprovado pela CAP de R $\$ 10$ milhões, e a SR Promoções Culturais Ltda., com o projeto Copacabana Reveillon 2015, no valor de R \$ 7,7 milhões. A soma dos valores aprovados para os cinco projetos selecionados chega a $26,2 \%$ do que foi destinado pela lei de incentivo cultural em 2014.

Para o ano de 2015 houve uma concentração maior dos recursos em poucos projetos, com $38,7 \%$ em cinco grandes projetos culturais. Desses cinco projetos culturais para esse ano, três tiveram 
ENTRE COPACABANA E MARQUÊS DE SAPUCAÍ: os rumos dos incentivos culturais

no Rio de Janeiro

um valor expressivo aprovado pela CAP. Assim como no ano anterior, a LIESA teve aprovado o projeto cultural Samba Patrimônio Cultural do Brasil, no mesmo valor do ano anterior, $\mathrm{R} \$ 10$ milhões. O proponente Rock World S.A, com o projeto cultural Rock in Rio 2015, teve aprovado o valor de R $\$ 10$ milhões, e a SR Promoções Culturais Ltda., com o projeto cultural Copacabana Reveillon 2016 no valor de $\mathrm{R} \$ 7$ milhões.

No último ano dessa série, em 2016, pode-se dizer que houve uma maior democratização dos recursos da lei de incentivo à cultura do estado do Rio de Janeiro. Foi o edital que teve o menor valor total concedido em benefício fiscal, R \$ 60,3 milhões. Porém, com o maior número de projetos aprovados. Os cinco maiores valores correspondem a $13,2 \%$ do volume concedido em renúncia fiscal, bem menor que os três anos da série. O projeto cultural com maior valor foi do mesmo proponente SR Promoções Culturais Ltda., com o projeto cultural Copacabana Reveillon 2017, porém, com um valor aprovado pela CAP de R $\$ 2$ milhões, equivalente a 3,7 vezes menor que a média dos outros anos. Também foi o único ano em que um projeto cultural do interior do estado ficou entre os cinco maiores. O projeto cultural do proponente Sagitário Cultural, Projeto e Produção de Eventos Culturais Ltda., com o projeto cultural Festival de Jazz \& Blues de Paraty - Bourbon Festival Parate, no município de Paraty, e no valor de R \$1,49 milhão.

A Tabela 3 expande um pouco mais a análise efetuada acima. Traz um perfil dos projetos aprovados pela CAP por dois extratos de valores, além de apontar os municípios a que se destinam. Mais uma vez, percebe-se a concentração desses projetos no município do Rio de Janeiro, que responde, em média por $38,8 \%$ desses projetos aprovados. Dos demais municípios, pode-se falar de Paraty e Petrópolis que aparecem com projetos nessa faixa de valor, ao logo desses quatro anos analisados. Mas, nenhum município aprovou mais que dois projetos acima dos valores considerados por essa análise. 
Mauro Macedo Campos | Luiza Oliveira Marquezine

Tabela 3 - Projetos aprovados pela SEC por extratos de valor (2013-2016)

\begin{tabular}{|c|c|c|c|c|}
\hline Ano & $\begin{array}{c}\mathrm{N}^{0} \text { de projetos } \\
\text { aprovados com } \\
\text { valor acima de } \\
\mathrm{R} \$ 1 \text { milhão }\end{array}$ & $\begin{array}{c}\mathrm{N}^{0} \text { de projetos } \\
\text { aprovados com } \\
\text { valor acima de } \mathrm{R} \$ \\
500 \mathrm{mil}\end{array}$ & $\begin{array}{c}\% \text { Total de } \\
\text { projetos } \\
\text { aprovados acima } \\
\text { de } \mathrm{R} \$ 500 \mathrm{mil}\end{array}$ & $\begin{array}{l}\text { Municípios / } \mathrm{N}^{0} \mathrm{de} \\
\text { projetos }\end{array}$ \\
\hline 2013 & 12 & 44 & 64,0 & $\begin{array}{l}\text { - Rio de Janeiro: } 39 \\
\text { - Nova Iguaçu: } 1 \\
\text { - Petrópolis: } 2 \\
\text { - Porto Real: } 1 \\
\text { - Rio Claro: } 1\end{array}$ \\
\hline 2014 & 13 & 56 & 66,4 & $\begin{array}{l}\text { - Rio de Janeiro: } 48 \\
\text { - Paraty: } 2 \\
\text { - Saquarema: } 1 \\
\text { - Petrópolis: } 1 \\
\text { - Valença: } 1 \\
\text { - Rio das Ostras: } 1 \\
\text { - Barra Mansa: } 1 \\
\text { - Niterói: } 1\end{array}$ \\
\hline 2015 & 16 & 42 & 79,9 & $\begin{array}{l}\text { - Rio de Janeiro: } 34 \\
\text { - Paraty: } 1 \\
\text { - Bangu: } 1 \\
\text { - Petrópolis: } 1 \\
\text { - Piraí: } 1 \\
\text { - Vassouras: } 1 \\
\text { - Valença: } 1 \\
\text { - Tinguá: } 1 \\
\text { - Rio das Ostras: } 1\end{array}$ \\
\hline 2016 & 16 & 37 & 56,6 & $\begin{array}{l}\text { - Rio de Janeiro: } 34 \\
\text { - Paraty: } 2 \\
\text { - Piraí: } 1 \\
\end{array}$ \\
\hline
\end{tabular}

Fonte: Elaborado pelos autores, conforme informaçōes do Diário Oficial do Estado do Rio de Janeiro (várias edições).

Esses projetos se concentram em áreas culturais. Ao longo desses quatro anos analisados observou-se uma concentração dos projetos aprovados e recursos de custeio. Por este último critério, como se observa no Gráfico 3, duas áreas se destacam, a música e a artes integradas. Juntas correspondem a quase $50 \%$ do volume de recursos destinados pela lei de incentivo à cultura no Rio de Janeiro. 
ENTRE COPACABANA E MARQUÊS DE SAPUCAÍ: os rumos dos incentivos culturais no Rio de Janeiro

Gráfico 3 - Principais áreas culturais em termos de aprovação de recursos por projeto 20.010

Fonte: Diário Oficial do Estado do Rio de Janeiro (várias edições). Elaborado pelos autores.

$\mathrm{O}$ fato de os produtores culturais do interior do estado do Rio de Janeiro disporem de poucos projetos aprovados pela lei de incentivo à cultura do Estado do Rio de Janeiro pode ser um indicador de uma baixa iniciativa dos produtores culturais nessa modalidade de custeio da produção cultural. Ou também, pode ser reflexo da carência de profissionalização dessa área de elaboração e captação de recursos, para projetos de renúncia tributária, nos municípios do interior. E, com isso, abre-se mão do acesso a uma fonte de recursos consideráveis (ainda que dependente da captação junto ao mercado), em um conjunto de municípios com grandes corporações empresariais que deixam de investir nas localidades onde exploram a matéria prima, como é o caso dos municípios que abrigam o maior complexo industrial de petróleo e gás do Brasil, que é a Bacia de Campos $\left(\mathrm{BC}^{7}\right)$ e que concentram os investimentos estatais e privados, no segmento petrolífero, justamente por ser o maior reservatório de petróleo e gás do país, correspondendo a mais de $80 \%$ de toda a produção offshore ${ }^{8}$.

Trata-se de uma ferramenta disponível aos produtores culturais que é acessível pelas leis de incentivo à cultura, em que pese o argumento da transferência pelo poder público da responsabilidade de captar os recursos no mercado, uma vez aprovado o mérito do projeto cultural pelo próprio estado. Ou seja, as iniciativas dos produtores culturais locais não se manifestaram em projetos que, ora submetidos à avaliação do estado, via leis de incentivo, não lograram resultado. Desse modo, apesar do acesso universal às leis de 
incentivo à cultura, na grande maioria dos municípios fluminenses tal condição não se efetivou na forma de aprovação e realização dos referidos projetos. Ao longo dos quatro anos analisados os dados mostraram uma média de 33 municípios do interior do estado com projetos aprovados, de um total de 91, fora a capital, Rio de Janeiro.

Portanto, assim como na grande maioria dos municípios do interior, não apenas no Rio de Janeiro, as leis de incentivo, tanto no âmbito federal como estaduais, não têm o mesmo impacto como percebido nas capitais e nos grandes centros. Trata-se de um questionamento frequente na literatura especializada sobre o grau de universalismo das respectivas leis. E não tem um único culpado. Longe disso. Na maioria dos municípios fluminenses observa-se o somatório das questões que desembocam nesse resultado: a baixa capacidade de as leis de incentivo à cultura se difundirem no interior. Isso porque, tem-se um desestímulo à capacitação profissional desses agentes culturais, a falta de conhecimento e de interesse em relação ao manuseio técnico/burocrático dos formulários das leis de incentivo à cultura, o desconhecimento do mercado e das empresas que comumente financiam esses projetos. São entraves enfrentados pelos produtores culturais do interior; afinal, a localidade onde realizam suas produções culturais não abrange o grande público e isso faz toda a diferença para o investidor que quer ver sua marca associada a projetos culturais de maior impacto. São, portanto, questões que podem ser percebidas pelo lado da oferta de bens e serviços culturais, tanto públicos, quanto privados. Acontece que pelo lado da demanda, ou seja, aqueles para os quais tais esforços são (se e quando são) direcionados pelo setor público e/ou privado, a resposta acaba se referindo a ações de curto prazo, que em boa medida, se materializam em política de eventos. E a reversão dessa condição não acontece do dia para a noite. Demanda atenção, gestão e tempo.

\section{CONCLUSÃO}

A partir de toda a problemática que envolve a área cultural no Brasil, sobretudo municípios do interior, pode-se dizer que as leis de incentivo fiscal à cultura, em específico da lei estadual, têm um caráter excludente, e isso nos leva a questionar: em que medida as leis de incentivo fiscal no âmbito federal e estadual beneficiam os produtores culturais locais? 
ENTRE COPACABANA E MARQUESS DE SAPUCAÍ: os rumos dos incentivos culturais

no Rio de Janeiro

As mais de três décadas de vigência das leis de incentivo à cultura (com suas alterações e derivações em nível subnacional) na esteira de um argumento liberal, conjugado com a escassez de recursos do estado, não foram capazes de criar uma cultura de investimentos, patrocínios, ou algo que o valha, junto aos municípios deslocados dos principais eixos das capitais, sobretudo, Rio de Janeiro e São Paulo. A extensa maioria dos municípios do interior do país não possui os mesmos atrativos inerentes aos grandes centros, como o público e a visibilidade. Afinal, nos grandes centros é que a circulação de pessoas e dinheiro se faz presente em muito maior intensidade, exatamente ao contrário das cidades do interior, que repulsam os grandes mecenas da cultura do Brasil.

Os agentes culturais do interior do estado não conseguiram se beneficiar através das leis. Iniciativas como a criação do Programa de Apoio ao Desenvolvimento Cultural, em 2010, para capacitar os produtores culturais em conjunto com o Ministério da Cultura, bem como a promoção de convênios e parcerias com instituições públicas ou privadas, ao que parece, não surtiram o efeito desejado. Ou seja, os produtores culturais do interior do estado continuam a não se beneficiar da lei de incentivo.

Por fim, apesar do êxito das leis de incentivo à cultura, não significa que o Estado esteja garantindo o direito ao acesso e à produção cultural a todos os cidadãos. Mesmo que os Ministérios e Secretarias aprovem os projetos julgando sua viabilidade e não o valor da obra, fica a cargo do mercado escolher; e, na maioria das vezes, optam por espetáculos que atraiam mais público, pois visam o marketing cultural. É o que se observou com os dados coletados junto à Secretaria de Estado da Cultura do Rio de Janeiro, onde observou-se a concentração de aprovação na capital e nas áreas culturais de artes integradas e música, tem como principais projetos culturais a Reforma da Sala Cecília Meireles, o Samba Patrimônio Cultural do Brasil, o Copacabana Reveillon, e o Rock in Rio, entre outros projetos culturais que evidenciam o já propalado pela literatura. Isso com o agravante de que os efeitos positivos esperados pelas leis de incentivo à cultura não aportam nos municípios do interior, como vem sendo identificado pelas pesquisas.

Nessa perspectiva, a produção cultural segue a lógica do mercado, a produção de arte inovadora, experimental, se dificulta por ser arriscada, comprometendo o investimento. Assim como as 
produções de caráter local não possuem visibilidade que possa interessar aos patrocinadores, a produção cultural nos estados menos industrializados fica prejudicada pela dificuldade de captar recursos junto ao mercado. (GALLOWAY; DUNLOP, 2007). Esse é um dos sérios problemas enfrentados pelos produtores culturais, fato que se agrava quando se pensa nos pequenos produtores, que lutam pelos mesmos recursos no mercado com produtores já consagrados, em um universo ao qual se soma a concorrência desequilibrada com os produtores independentes, sobretudo das pequenas cidades afastadas dos grandes centros.

\section{REFERENCIAS}

BOTELHO, I. Dimensões da Cultura e Políticas Públicas. Perspectiva, São Paulo, v. 15, n. 2, abr.jun, 2001.

CALABRE, L. Políticas "Culturais no Brasil: balanço e perspectivas". In: RUBIM, A. A. C. (Org.). Políticas culturais no Brasil. Salvador : EDUFBA, 2007. (Coleção CulT).

COSTA, C. F.; MEDEIROS, I. B. de O.; BUCCO, G. B. O

financiamento da cultura no Brasil no período 2003-15: um caminho para geração de renda monopolista. Revista de Administração Pública, Rio de Janeiro, v. 51, n. 4, p. 509-527, jul./ago. 2017.

DURAND, J. C. Cultura como objeto de Política. In: Política Cultural e Economia da Cultura. São Paulo: Ateliê Editorial/SESC, 2001.

; GOUVEIA, M. A.; BERMAN, G. Patrocínio empresarial e incentivos fiscais à cultura no brasil: análise de uma experiência recente. REA - Revista de Administração de Empresas, São Paulo, v. 37, n. 4, p.38-44, out./dez. 1997.

GALLOWAY, S.; DUNLOP, S. A critique of definition of the cultural and creative industries in public policy. International Journal of Cultural Policy, [S. 1.], v. 13, n. 1, p. 17-31, 2007.

JESSOP, B. Cultural political economy and critical policy studies. Critical Policy Studies, [S. 1.], v. 3, n. 3/4, p. 336-356, 2009.

MOISÉS, J. Á. Os efeitos das leis de incentivo à cultura. In: WEFFORT, F. C.; SOUZA, M. (Orgs.). Um olhar sobre a cultura. 1. ed. Rio de Janeiro: MinC, 1998. v. 1, p. 421-444.

RIO DE JANEIRO. Secretaria de Cultura. Curso de Formação de Gestores Públicos e Agentes Culturais Rio de Janeiro. Lei de 
ENTRE COPACABANA E MARQUÊS DE SAPUCAÍ: os rumos dos incentivos culturais

no Rio de Janeiro

Incentivo à Cultura do Estado do Rio de Janeiro. Rio de Janeiro, 2013. Oferecido por Tatiana Richard Disponível em:<http://www.cultura. rj.gov.br/curso-gestores-agentes/textos/leiincrj.pdf $>$. Acesso em: 1 dez. 2017

. Decreto n ${ }^{\circ} 45.419$, de 19 de outubro de 2015. Institui o Sistema Estadual de Cultura do Estado do Rio de Janeiro, o Programa Estadual de Fomento e Incentivo à Cultura, e as Diretrizes e Estratégias do Plano Estadual de Cultura, 2015. Rio de Janeiro, 2015. Disponível em: $<$ http://www.cultura.rj.gov.br/download-documentoprojeto/decretoregulamentacaoconselho_1445611954.pdf $>$. Acesso em: 1 dez. 2017

Plano Estadual de Cultura - Relatório de Atividades Programa de Apoio ao Desenvolvimento Cultural dos Municípios do Estado do Rio de Janeiro (PADEC). Rio de Janeiro, 2010. Disponível em: $<$ http://www.cultura.rj.gov.br/download-documento-projeto/ relatorio_padec_1287498242.pdf $>$. Acesso em: 1 dez. 2017

Superintendência da Lei de Incentivo. Benefício Fiscal (2008 a 2012). Rio de Janeiro, 2012. Disponível em: $<\mathrm{http}: / /$ www.cultura.rj.gov.br/leidoincentivo/docsli/dados da lei de incentivo_14082013_revisado.pdf>. Acesso em: 1 dez. 2017

RUBIM, A. A. C. Políticas culturais do governo Lula. Revista Lusófona de Estudos Culturais, Aveiro, v. 1, n. 1, p. 224-242, 2013

Políticas culturais do governo Lula/Gil: desafios e enfrentamentos. Intercom - Revista Brasileira de Ciências da Comunicação, LOCAL, v. 31, n. 1, p.183-204, jan./jun. 2008.

Políticas culturais e novos desafios. Revista Matrizes, São Paulo, ano 2, n. 2, p. 93-115, 2009.

SANTOS, E. G.; DE PAULO, C. B. Gastos tributários e recursos orçamentários nas políticas Culturais. Revista de Políticas Públicas, São Luís, v. 18, n. 1, p. 111-124, jan./jun. 2014.

SILVA, F. A. B.; MIDLEJ, S. Políticas Públicas Culturais: a voz dos gestores. Brasília, DF: IPEA, 2011.

\section{Notas:}

1 A lei leva este nome em homenagem ao secretário de cultura, á época em que a legislação foi formulada, Sérgio Paulo Rouanet.

2 De uma maneira geral os investimentos pelas leis de incentivo à cultura concentram-se nas capitais, sobretudo na região Sudeste, no eixo Rio-São Paulo. Mais especificamente para este artigo, no estado do Rio de Janeiro, para os anos analisados, foi destinado em 
média, $13,9 \%$ dos recursos da lei de incentivo à cultura para os municípios do interior do estado. Com destaque para os municípios de Paraty e Petrópolis que tiveram projetos aprovados com valores acima de R $\$ 500$ mil. Dentre esses projetos, destaca-se em Paraty: a Festa Literária Internacional de Paraty (em três edições) e o Festival de Jazz \& Blues de Paraty. Já em Petrópolis foram: o Projeto de Digitalização do Acervo do Museu Imperial, o Bauernfest Petrópolis, o Festival de Artes e Leitura de Petrópolis e o Projeto Recicla Vida (em três edições). Mas ainda assim, pouco expressivos frente ao volume destinado aos projetos culturais da capital.

3 Para o desenvolvimento deste artigo entende-se como grandes corporações, aqueles grupos empresarias que detém uma fração importante dos mercados que atuam. Utilizam de estratégias de marketing mix, onde os investimentos em cultura ocupam espaços importantes. No caso específico do Rio de Janeiro, a Secretaria de Estado de Cultura Superintendência da Lei de Incentivo (2012) traz um rankeamento das cinco principais empresas que financiam a cultura no estado, sendo: Petrobrás, Telemar, Light, Ambev e Coca-Cola. Já em termos dos grandes financiadores nacionais, pela Lei Rouanet, os principais são: Petrobras, Vale do Rio Doce, Banco do Brasil, BNDES, Eletrobras, Bradesco, Itaú, Fiat. Ver no site da Secretaria da Cultura (Disponível em: $<$ http://www. cultura.rj.gov.br/leidoincentivo/docsli/dados_da_lei_de_incentivo_14082013_revisado. pdf $>$.

4 Ver no site da Secretaria da Cultura (Disponível em: $<$ http://www.cultura.gov.br/ site/2008/11/14/a-cultura-esta-refem-da-renuncia-fiscal/>.

5 Ver Art $1^{\circ}, \S 1^{\circ}$, da Lei $n^{\circ} 1.954$, de 26 de janeiro de 1992.

6 Ver art. $11^{\circ}$ do Decreto $n^{\circ} 44.013,2$ de janeiro de 2013, onde estabelece que: "Será admitida em caráter excepcional, por decisão conjunta do Secretário de Estado Chefe da Casa Civil e do Secretário de Estado de Cultura, a inscrição de projeto cultural fora dos editais, desde que: I) o projeto cultural represente oportunidade única para promover o enriquecimento da cultura fluminense; II) a realização do projeto cultural esteja condicionada a uma data específica; III) apresentação da Declaração de Patrocínio".

7 A BC possui atualmente 55 campos de petróleo, com 826 poços exploratórios. Estes poços de petróleo estão vinculados a 45 plataformas marítimas, sendo 41 plataformas de produção e quatro de processamento. A liderança neste ambiente empresarial competitivo cabe à Petrobras, que divide espaço com cinco grandes corporações privadas do setor petrolífero: a HRT Participações em Petróleo; a OGPar Óleo e Gás Participações; a Chevron Corporation Brasil; a Shell Brasil; OGX; e a Statoil. Todas são compostas por capital estrangeiro, sendo as duas primeiras, consórcios que contam com capital nacional.

8 As plataformas de extração de petróleo podem ser no continente, em terra firme, sendo denominadas de plataforma onshore ou no mar, que são as chamadas plataforma offshore, possuindo uma estrutura moderna de perfuração em alto mar, abrigando trabalhadores e equipamentos necessários na perfuração de poços, além da extração de petróleo e gás. Tais plataformas podem ser fixas no solo marinho, ou flutuantes. 